\title{
Alz-50 Recognizes a Phosphorylated Epitope of Tau Protein
}

\author{
K. Uéda, ${ }^{1}$ E. Masliah, ${ }^{1}$ T. Saitoh, ${ }^{1}$ S. L. Bakalis, ${ }^{2}$ H. Scoble, ${ }^{3}$ and K. S. Kosik ${ }^{2}$ \\ 'Department of Neurosciences, School of Medicine, and Center for Molecular Genetics, University of California at San \\ Diego, La Jolla, California 92093, 2Department of Neurology (Neuroscience), Harvard Medical School, and Center for \\ Neurologic Diseases, Department of Medicine (Division of Neurology), Brigham and Women's Hospital, Boston, \\ Massachusetts 02115, and ${ }^{3}$ Genetics Institute, Inc., Cambridge, Massachusetts 02140 and Massachusetts Institute of \\ Technology, Cambridge, Massachusetts 02139
}

\begin{abstract}
Alz-50 is a monoclonal antibody that detects antigens enriched in the brain tissue of Alzheimer's disease (AD) patients. Although Alz-50 recognizes $\tau$, an identified integral constituent of the AD paired helical filament (PHF), the exact nature of the antigenic site is unknown. An immunoblot analysis demonstrated that the antigenic sites to $\mathrm{Alz}-50$ are diminished by acid phosphatase treatment. Consistent with this finding, Alz-50 antigens were more concentrated in brain homogenates prepared with phosphatase inhibitors. The epitope in $\tau$ with which Alz-50 reacts is located in the carboxy terminus within a 14-amino acid region from just beyond the microtubule-binding repeats to the carboxy terminus. An isolated carboxy-terminal chymotryptic peptide from bovine brain $\tau$ reactive with Alz-50 was analyzed by fast-atom-bombardment mass spectroscopy (FAB-MS) and was found to be present as both a monophosphopeptide and a nonphosphorylated peptide. The immunohistological analysis has demonstrated that Alz-50 staining of neurofibrillary tangles (NFTs) is sensitive to acid phosphatase but not to alkaline phosphatase. Furthermore, Alz-50 staining of NFTs was effectively adsorbed by a high concentration of phosphoserine but not by serine or phosphothreonine. These results strongly suggest that Alz-50 recognizes a phosphorylated epitope in the carboxy terminus of $\tau$ which has not been previously detected by using alkaline phosphatase. The strong Alz-50 staining in AD samples may represent another association between a phosphorylation state and neurofibrillary lesions. As a marker of the inchoate tangle-bearing neuron, the characterization of the Alz-50 epitope in $\tau$ offers a partial molecular basis for the modifications that contribute to the assembly of PHFs.
\end{abstract}

Tau $(\tau)$ is a phosphoprotein found primarily in neural tissue (Binder et al., 1985; Kowall and Kosik, 1987) and represents 1 member of the class of mammalian brain microtubule-associ-

\footnotetext{
Received Jan. 10, 1990; revised Apr. 16, 1990; accepted May 23, 1990.

We thank Drs. P. Davies, L. I. Binder, J. Wang, M. White, and R. Fracklcton for generously providing antibodies, K. Biemann for use of the MIT Mass Spectroscopy Facility, and $\mathrm{R}$. Terry and $\mathbf{R}$. Katzman for critically reading the manuscript. The authors also thank Drs. Gloria Lee and Hideyo Inouye for helpful discussions and Margaret Ehrhardt for help with peptide sequencing. This work was supported by NIH Grants AG05131, AG08205, AG06601, and AG06172 and by grants from the McKnight Endowment Fund for Neuroscience and the Pew Charitable Trust.

Correspondence should be addressed to Dr. T. Saitoh, Department of Neurosciences, School of Medicine (M-024), University of California at San Diego, La Jolla, CA 92093.
}

Copyright (C) 1990 Society for Neuroscience $0270-6474 / 90 / 103295-10 \$ 03.00 / 0$ ated proteins (MAPs). For reasons that are unclear, $\tau$ alone among the various microtubule proteins either self-assembles or co-assembles with some other, as yet unidentified protein into the paired helical filament (PHF). Many distinct $\tau$ epitopes are immunochemically detectable in the PHF (Kosik et al., 1988), and direct analysis of pronase-digested material of SDS-insoluble residues has yielded sequences derived from the carboxyterminal domain of $\tau$ (Kondo et al., 1988; Wischik et al., 1988). The monoclonal antibody Alz-50, along with some anti- $\tau$ antibodies, recognizes populations of hippocampal, entorhinal, and cortical pyramidal neurons vulnerable to the development of neurofibrillary tangles (NFTs) before they actually form discrete NFT, while normal neurons are not labeled (Hyman et al., 1988; Bancher et al., 1989). On immunoblots, Alz-50 recognizes all the human $\tau$ protein isoforms observed in both the adult and the fetal brain, and bovine $\tau$ protein can adsorb out this staining (Ksiezak-Reding et al., 1988; Nukina et al., 1988). Although a staining pattern similar to Alz-50 has been reported for some other $\tau$ antibodies (Joachim et al., 1987; Trojanowski et al., 1989), Alz-50 immunoreactivity is the most robust. Alz-50 also labels neurons destined for programmed neuronal cell death (AlGhoul and Miller, 1989).

Tau amino acid sequences have been deduced from murine, bovine, and human cDNAs (G. Lee et al., 1988, 1989; Goedert et al., 1989; Himmler et al., 1989; Kosik et al., 1989; Mori et al., 1989), and, from these data, a complex picture of alternatively spliced isoforms has emerged. Tau protein also exists in at least 2 distinct phosphorylation states (Lindwall and Cole, 1984b); however, the microheterogeneity of $\tau$ by 2-dimensional gels has raised the possibility of multiple phosphorylation states (Butler and Shelanski, 1986). The kinase(s) responsible for the in vivo phosphorylation of $\tau$ are not known, though crude $\tau$ preparations have been considered good substrates for $\mathrm{Ca}^{2+}$ calmodulin-dependent protein kinase II (CaM kinase II) (Yamamoto et al., 1983; Schulman, 1984). Under recently described conditions, purified $\tau$ has served as a substrate capable of phosphate incorporation to the level of stoichiometry with $\mathrm{CaM}$ kinase II (Baudier and Cole, 1987). Protein kinase C (PKC) has also been shown to phosphorylate $\tau$ in vitro (Baudier et al., 1987; Hoshi et al., 1987), and a novel kinase dependent on tubulin can phosphorylate $\tau$ in vitro (Ishiguro et al., 1988).

Phosphorylated forms of $\tau$ have been detected in NFTs and the suggestion has been made that the phosphorylation of $\tau$ in tangles of Alzheimer's disease (AD) is aberrant (Grundke-Iqbal et al., 1986; thara et al., 1986). One suggested site of aberrant phosphorylation has been the epitope for the monoclonal 
antibody Tau-1, located approximately in the middle of the molecule (Kosik et al., 1988). The second site of aberrant $\tau$ phosphorylation in AD has been localized recently close to the amino-terminal end (Iqbal et al., 1989). Despite the staining of $\tau$ by Alz-50, when $\tau$ is expressed in bacteria, it is not reactive with Alz-50 (Kosik et al., 1988), a finding that has prompted the study of a posttranslational modification as part of the epitope. Direct analysis of $\tau$ in the AD brain has suggested that a modified form of $\tau$ is present in AD (Nieto et al., 1988), and it is possible that $\Lambda \mathrm{lz}-50$ may be directed against a modification of $\tau$ that occurs early in the sequence of events leading to neurofibrillary degeneration or programmed neuronal cell death.

Identification of posttranslational modifications in $\tau$ and the determination of their relation to the PHF may uncover the nature of the aberrant cellular homeostasis in tangle-bearing neurons. The data presented here of a phosphorylation site either within or adjacent to the Alz-50 epitope and of the phosphatase sensitivity of Alz-50 reactivity further implicate a phosphorylation event in the genesis of the NFT. This region of the molecule may have a role in the assembly of $\tau$ into the inert insoluble polymers found in PHFs.

\section{Materials and Methods}

Tissue preparation. Preparation of human brain tissue was modified from previous studies (Saitoh and Dobkins, 1986; Nukina et al., 1988). Frozen cerebral midfrontal cortex from $A D$ and normal human postmortem brains was homogenized in $10 \mathrm{vol}$ of the homogenization buffer [5 mm HEPES ( $\mathrm{pH}, 8.0), 0.32 \mathrm{~m}$ sucrose, $5 \mathrm{~mm}$ benzamidine, $2 \mathrm{~mm}$ $\beta$-mercaptoethanol, $3 \mathrm{~mm}$ EGTA, $0.5 \mathrm{mM} \mathrm{MgSO}_{4}, 10 \mu \mathrm{g} / \mathrm{ml}$ leupeptin, $5 \mu \mathrm{g} / \mathrm{ml}$ pepstatin $\mathrm{A}, 0.1 \mathrm{mg} / \mathrm{ml}$ aprotinin, $0.3 \mathrm{~mm}$ phenylmethylsulfonyl fluoride] with or without phosphatase inhibitors $(50 \mathrm{~mm}$ imidazole, 50 mм potassium fluoride, $50 \mathrm{~mm} \beta$-glycerophosphate, $50 \mathrm{~mm}$ tetrasodium pyrophosphate, $100 \mu \mathrm{M}$ sodium ortho-vanadate, $0.1 \mathrm{mM}$ zinc chloride) using a Polytron homogenizer (Brinkman, Westbury, NY) and centrifuged at $1000 \times g$ for $30 \mathrm{~min}$ at $4^{\circ} \mathrm{C}$ to precipitate nuclei and unbroken debris. The $1000 \times g$ supernatant was centrifuged at $10,000 \times g$ for 1 $\mathrm{hr}$ at $4^{\circ} \mathrm{C}$ to separate the membrane-rich fraction $(10,000 \times g$ pellet $)$ from the cytosol. The $10,000 \times g$ supernatant was then centrifuged at $200,000 \times g$ for $4 \mathrm{hr}$ at $4^{\circ} \mathrm{C}$ to obtain the Alz-50 antigen-rich fraction $(200,000 \times g$ pellet $)$.

Preparation of $\tau$ protein. Tau protein was prepared according to a modification of the method described by Baudier et al. (1987). Up to 3 fresh calf brains weighing approximately $500-600 \mathrm{gm}$ were homogenized in $1 \mathrm{ml} / \mathrm{gm}$ initial buffer $\left[0.1 \mathrm{M} \mathrm{KH}_{2} \mathrm{PO}_{4}, 2 \mathrm{mM}\right.$ EDTA, $2 \mathrm{mM}$ EGTA, $2 \mathrm{mM} \beta$-mercaptoethanol, $0.3 \mathrm{~mm}$ phenylmethylsulfonyl fluoride, $10 \mu \mathrm{g} / \mathrm{ml}$ leupeptine, $10 \mu \mathrm{g} / \mathrm{ml}$ aprotinin, $10 \mu \mathrm{g} / \mathrm{ml}$ pepstatin $\mathrm{A}, 5$ $\mathrm{mm}$ benzamidine $(\mathrm{pH}, 6.9)]$ and centrifuged for $30 \mathrm{~min}$ at $13,000 \times \mathrm{g}$. The supernatant was brought to $45 \%$ saturation with ammonium sulfate $(\mathrm{pH}, 7.5)$ and agin spun at $13,000 \times \mathrm{g}$ for $30 \mathrm{~min}$. The pellet was resuspended in initial buffer $(\mathrm{pH}, 6.9)$ and dialyzed against the same buffer $(\mathrm{pH}, 6.5)$. The cleared dialysate was added to $\mathrm{CM}$ Sephadex [8 $\mathrm{gm}$ swollen and equilibrated to $280 \mathrm{ml}$ in initial buffer $(\mathrm{pH}, 6.5)]$ stirred for $30 \mathrm{~min}$, and filtered through a Buchner funnel with Whatman 1 filter paper. The filtrate was poured onto a chromatographic column and washed until the optical density was less than 0.01 . Protein was eluted with $0.5 \mathrm{M} \mathrm{NaCl}$ in initial buffer $(\mathrm{pH}, 6.5)$, and perchloric acid was added to $2.5 \%$. The sample was spun for $15 \mathrm{~min}$ at $15,000 \times \mathrm{g}$, and the supernatant was again precipitated with $45 \%$ saturated ammonium sulfate. In preparation for high-pressure liquid chromatography (HPLC) (Waters 650), the precipitate was taken up in buffer $\mathrm{A}[0.1 \mathrm{M}$ Tris- $\mathrm{HCl}$ $(\mathrm{pH}, 7.2), 1 \mathrm{~mm}$ dithiothreitol] and loaded onto a Protein Pak DEAE-5 PW column $(8.0 \mathrm{~mm} \times 7.5 \mathrm{~cm}$, Waters). Elution was programmed to reach $1.0 \mathrm{M} \mathrm{NaCl}$ in $30 \mathrm{~min}$ with the fractions monitored at $280 \mathrm{~nm}$. After this procedure, only a few low-molecular-weight contaminants were present. To obtain pure $\tau$ (as well as desalting), a final sieving step by HPLC used a Waters Protein Pac 300SW $(7.5 \mathrm{~mm} \times 30 \mathrm{~cm})$ in 100 $\mathrm{mm}$ ammonium bicarbonate and $1 \mathrm{~mm}$ dithiothreitol with a $30-\mathrm{min}$ isocratic profile.
Immunoblot analysis. Brain samples were electrophoresed on 8-16\% SDS-polyacrylamide gels. The proteins on the gel were electrotransferred to nitrocellulose paper (Towbin et al., 1979), successively incubated with $0.1 \%$ Tween-20 in PBS, mouse monoclonal antibody Alz-50 (1: 50; Wolozin et al., 1986) or Tau-1 (1:2000; Binder et al., 1985), and ${ }^{125} \mathrm{I}$-sheep anti-mouse IgG $(1 \mu \mathrm{Ci} / \mathrm{ml}, 0.4 \mu \mathrm{Ci} / \mu \mathrm{g} ; \mathrm{ICN}$, Costa Mesa, CA $)$, followed by autoradiography at $-70^{\circ} \mathrm{C}$.

Phosphatase treatment. Proteins blotted on nitrocellulose paper were treated with acid or alkaline phosphatases as follows: After blocking by $0.1 \%$ Tween-20, nitrocellulose strips were treated either with the mixture of acid phosphatases from human semen ( 2 units $/ \mathrm{ml}$; Sigma) and white potato ( 5 units $/ \mathrm{ml}$; type VII, Sigma) in $0.1 \mathrm{~m}$ acetate buffer $(\mathrm{pH}$, 4.8 ) or with alkaline phosphatases from human placenta $(15 \mathrm{units} / \mathrm{ml}$; type XXIV, Sigma) bovine kidney (14 units/ml; typeXXXI, Sigma), bovine intestine ( 25 units $/ \mathrm{ml}$; type VII-S, Sigma), and Escherichia coli (8.8 units/ml; type III, Sigma) in $0.1 \mathrm{M}$ diethanolamine $(\mathrm{pH}, 9.8)$ containing leupeptine $(0.1 \mathrm{mg} / \mathrm{ml})$, aprotinin $(0.1 \mathrm{mg} / \mathrm{ml})$, and pepstatin $A$ $(0.05 \mathrm{mg} / \mathrm{ml})$. The strips were treated for $3 \mathrm{hr}$ at $37^{\circ} \mathrm{C}$, followed by immunostaining as described above. Alkaline phosphatase incubation contained $0.5 \mathrm{mM} \mathrm{MgCl} 2$ because this enzyme requires $\mathrm{MgCl}$ for its activity.

Tau cleavage and fragment analysis. Purified $\tau(1.5 \mathrm{mg})$ was partially digested with $20 \mu \mathrm{g}$ chymotrypsin for $3 \mathrm{~min}$ at $37^{\circ} \mathrm{C}$, then the reaction was stopped with 2 mm phenylmethylsulfonyl fluoride. The digest was loaded onto an HPLC (Spectra Physics) and separated with a Vydac C4 reverse-phase column using $0.1 \%$ trifluoroacetic acid and $80 \%$ acetonitrile as the mobile phase at a flow rate of $0.5 \mathrm{ml} / \mathrm{min}$. Either $1-$ or $0.5-\mathrm{ml}$ fractions were collected and lyophilized. Fractions were analyzed by dot blotting with $\mathrm{Alz}-50$ and sequenced from glass-fiber disks by automated Edman degradation on an Applied Biosystems (Foster City, CA) 470A gas-phase sequenator. The phenylthiohydantoin (PTH) amino acid derivatives were identified and quantified on a Waters 840 HPLC system.

Fast-atom-bombardment mass spectrometry ( $F A B-M S)$. FAB-MS was recorded using a JEOL HX110 high-resolution mass spectrometer operated at $10-\mathrm{kV}$ accelerating voltage (Biemann, 1986). Samples were introduced via a direct insertion probe through a vacuum lock into the ion source. The sample matrix was bombarded by xenon atoms that had been accelerated to $8 \mathrm{kV}$, and the instrument was set at a resolution of $1: 1000$. Samples to be analyzed were dissolved in $1.0 \mu 1$ glycerol and $30 \%$ acetic acid $(5: 1, v / v)$, and $0.5 \mu \mathrm{l}$ was applied to the probe tip.

Inorganic phosphate content of $\tau$. Inorganic phosphate in $\tau$ protein purified by the taxol method (Vallee, 1982) both with and without phosphatase inhibitors was performed by the method of Stul and Buss (1977). The phosphatase inhibitors were present at all stages of the preparation. A Beckman 6300 amino acid analyzer was used for the accurate quantification of protein in each sample. An average molecular weight of 55,000 was used for $\tau$.

Immunochemical probes for phosphotyrosine. The association of a phosphotyrosine was sought with NFTs on the brain section, and $\tau$ was prepared in the presence of phosphatase inhibitors. An affinity-purified polyclonal antiserum raised against a v-abl encoded protein and specific for phosphotyrosine was the gift of Dr. Jean Wang (Morla and Wang, 1986). A second anti-phosphotyrosine raised against $N$-bromoacetyl- $o$ phosphotyramine was obtained from Dr. Morris White (White et al., 1985). A monoclonal anti-phosphotyrosine was obtained from Dr. Raymond Frackleton (Daniel et al., 1985).

Immunohistochemistry. Formalin-fixed, paraffin-embedded, $7-\mu \mathrm{m}$ serial sections of the AD hippocampus and frontal cortex were mounted onto gelatin slides for immunolabeling.

To determine the sensitivity of the $\mathrm{AD}$ tissue to phosphatase treatment, a group of sections was washed for $10 \mathrm{~min}$ in $0.025 \%$ Triton $\mathrm{X}-100$ in Tris-buffered saline (TBS) followed by incubation for $2 \mathrm{hr}$ at $37^{\circ} \mathrm{C}$ with serial dilutions of acid phosphatase prepared as previously described for Western blot. Control sections were pretreated with 0.1 m acetate buffer $(\mathrm{pH}, 4.8)$ or $0.2 \mathrm{M}$ TBS $(\mathrm{pH}, 7.4)$ or alkaline phosphatase (Love et al., 1988) for $2 \mathrm{hr}$ at $37^{\circ} \mathrm{C}$. All sections were washed in TBS followed by blocking with $1 \%$ normal horse serum and overnight incubation at $4^{\circ} \mathrm{C}$ with Alz-50 $(1: 10)$ or Tau- $1(5 \mu \mathrm{g} / \mathrm{ml})$. The slides were developed by incubation in biotinylated horse anti-mouse IgG, avidinHRP (ABC Vector) and diaminobenzidine solution $[0.4 \mathrm{mg} / \mathrm{ml}$ in Tris$\mathrm{HCl}$ buffer $(\mathrm{pH}, 7.4)$ with $45 \mu 130 \% \mathrm{H}_{2} \mathrm{O}_{2}$ ].

To determine which phosphoamino acid adsorbed Alz-50 immunoreactivity, another group of serial sections was incubated with Alz$50(1: 10)$ or Alz-50 $(1: 10)$ mixed overnight at $4^{\circ} \mathrm{C}$ with one of the 


\section{Alz-50}

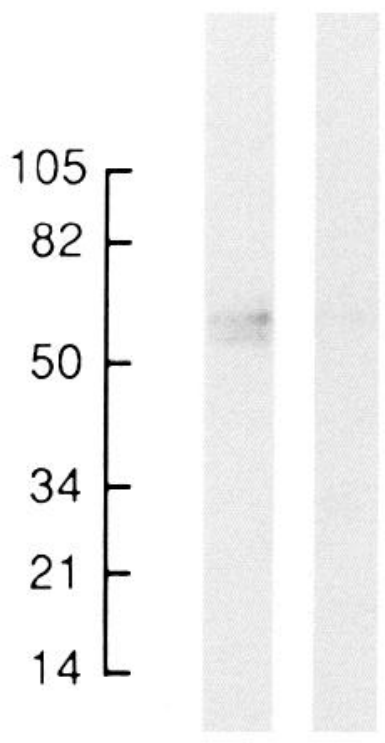

\section{Phosphatase}

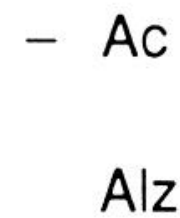

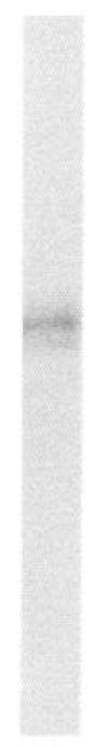
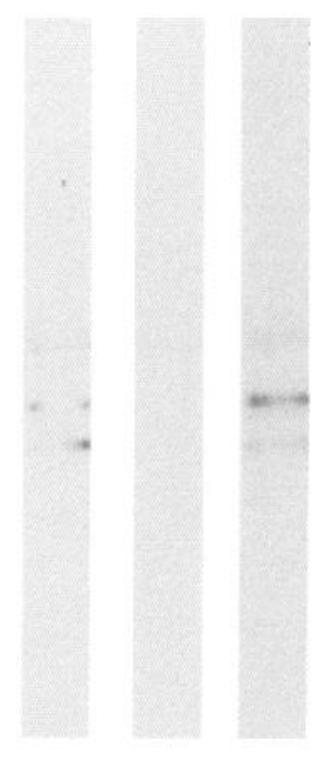

$-\operatorname{Ac~Al}$

Fetal

\section{Tau-1}
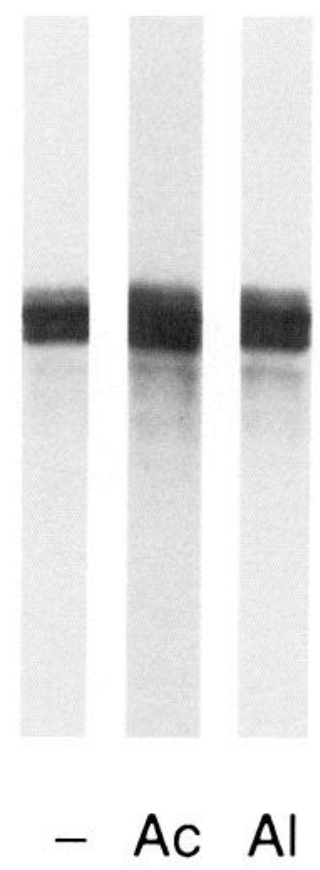

Alz
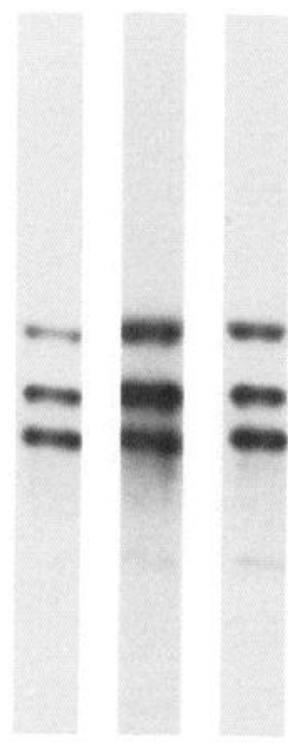

$-\mathrm{Ac} \mathrm{Al}$

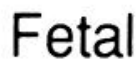

Figure 1. Effect of phosphatase treatment of protein blot. Fifty $\mu \mathrm{g}$ proteins from high-speed pellet fractions prepared without phosphatase inhibitors were Western blotted, treated with acid phosphatase $(A C)$ or alkaline phosphatase $(A l)$ or without phosphatase $(-)$ as described under Materials and Methods, and immunostained with Alz- 50 or Tau-1. This autoradiogram was developed after 3 days of exposure at $-70^{\circ} \mathrm{C}$ with intensifying screens. Alz, AD cortex; Fetal, fetal cerebral tissue.

following aminoacids (Sigma, St. Louis, MO): phosphoserine $(0.1 \mathrm{M})$ phosphothreonine $(0.1 \mathrm{M})$, serine $(0.1 \mathrm{M})$, or threonine $(0.1 \mathrm{M})$. Control sections were incubated with Alz-50 mixed with PBS (pH, 7.4;0.1 M) and with standard culture medium. The slides were developed as described above.

To estimate the effect of the different conditions on Alz-50 immunolabeling the total number of immunostained plaques and tangles in areas CA4-CA1 and the subiculum were manually quantified, added, and averaged.

\section{Results}

Alz-50 staining on Western blot is sensitive to acid phosphatase

The presence of Alz-50 antigenicity has been described in both supernatant or pellet fractions, depending on the method used (Wolozin et al., 1986, 1988; Love et al., 1988; Nukina et al., 1988). Under our experimental conditions, about $70 \%$ of the Alz-50 reactivity was recovered in the $200,000 \times g$ pellet regardless of whether normal, $\mathrm{AD}$, or fetal brain was used. In the current experiments, normal samples were not studied further. Alz-50 stained a doublet of $\sim M_{\mathrm{r}} 60,000$ in the AD high-speed pellet (Fig. 1), which was also stained with the anti- $\tau$ antibody, Tau-1. When the blot was treated with a mixture of acid phosphatases, Alz-50 staining was markedly reduced, whereas alkaline phosphatase treatment did not have any detectable effect on the reactivity. Identical treatment of immunoblots with the phosphatase mixture enhanced Tau-1 staining. The effect of the acid phosphatase does not seem to be due to the contaminating protease, because the inclusion of the phosphatase inhibitors but not the protease inhibitors abolished the effect of acid phosphatase (data not shown). Furthermore, blot treatment with protease $\mathrm{K}(10 \mu \mathrm{g} / \mathrm{ml})$ abolished both Alz-50 and Tau-1 reactivity, supporting the specificity of phosphatase (data not shown).

To determine whether the acid-phosphatase sensitivity of Alz50 was exclusively a feature of AD samples, we repeated the experiment in fetal tissue where Alz-50 staining is prominent. In an immunoblot of fetal brain high-speed pellet, Alz-50 revealed a triplet of reactive bands between $\sim M_{\mathrm{r}} 40,000$ and $\sim M_{\mathrm{r}}$ 50,000 (Fig. 1). All 3 bands were also recognized by Tau-1. Acid phosphatase treatment of the blot reduced Alz-50 staining of these bands, whereas alkaline phosphatase treatment did not. Again, Tau-1 staining of the bands was enhanced by both phosphatase treatments of the blots. The same results were obtained with 4 different AD brains and 2 fetal brains. Quantification of the effect of the phosphatases showed that acid phosphatase reduced Alz-50 staining of the AD doublet by $60 \%(p<0.01)$, whereas alkaline phosphatase did not have any effect. Tau-1 staining of this doublet was increased by $30 \%(p<0.05)$ by both acid and alkaline phosphatase treatment.

\section{Alz-50 reactivity with purified $\tau$ protein}

We partially purified a carboxy-terminal $\tau$ peptide. Tau protein extracted from 500 gm wet-weight bovine brain yielded from 
A

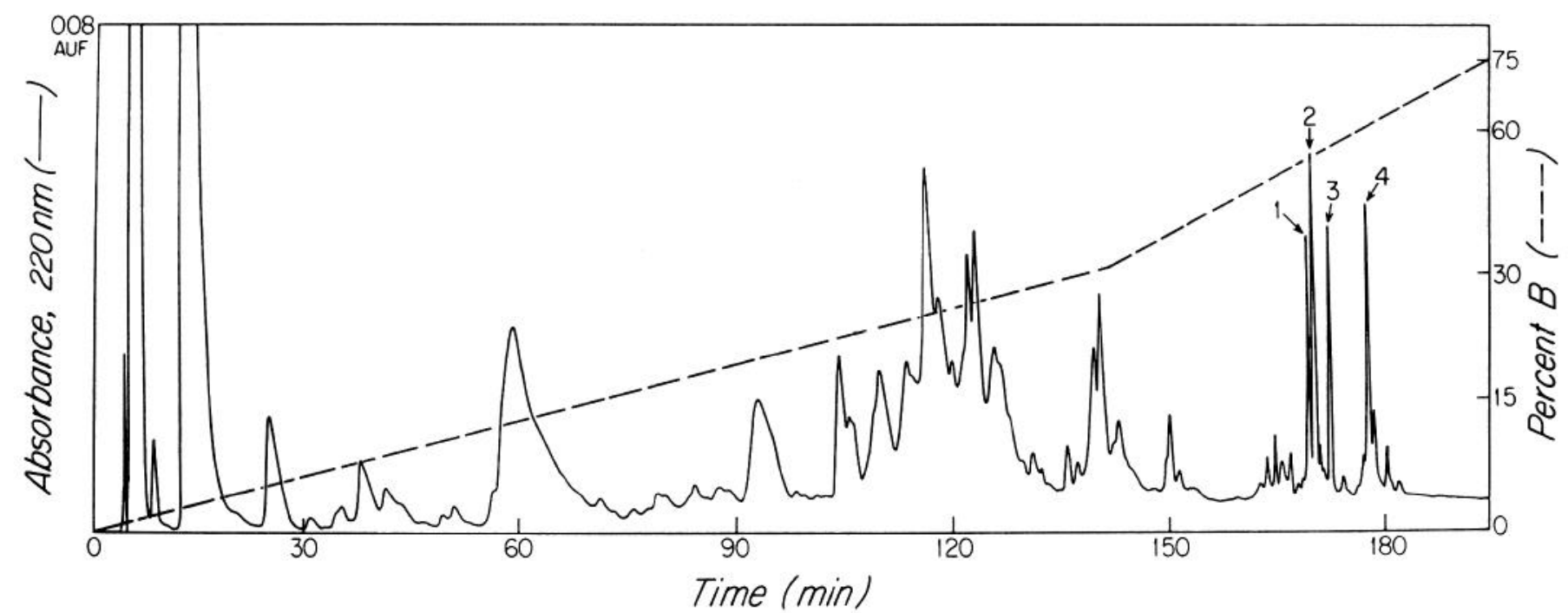

B

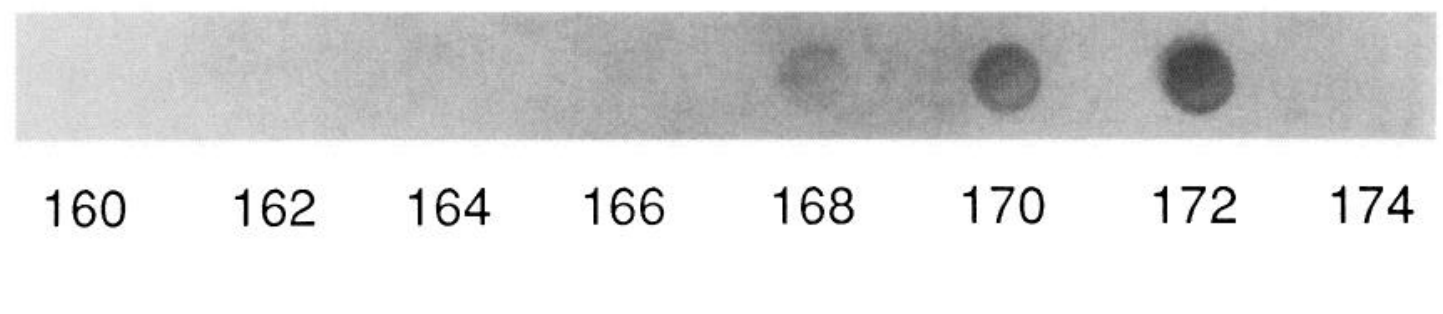

Figure 2. HPLC analysis. A, Reverse-phase HPLC of $\tau$ partial chymotryptic digest. Uncleaved $\tau$ and very large fragments are clustered in the series of peaks around $120 \mathrm{~min}$. At later retention times, there is no Alz-50 reactivity until the peaks labeled 1-3 appear, which represent carboxyterminal fragments of $\tau$. Peak 4 may not be a protein peak. B, Alz-50 dot blot of HPLC fractions. Ten percent of the sample eluted into each 0.5 $\mathrm{ml}$ fraction was dotted onto nitrocellulose, placed in a Biodot chamber (BioRad), and reacted with Alz-50. Fractions between 160 and 174 min are illustrated, and the only reactive fractions correspond to peaks $1-3$ in $A$.

1.5 to $7 \mathrm{mg}$ pure $\tau$ after the final chromatography steps (see Materials and Methods). The purified $\tau$ fraction was briefly treated with chymotrypsin as described by Ksiezak-Reding et al. (1988) to retain Alz-50 immunoreactivity, and the products were separated by reverse-phase HPLC (Fig. 2). A highly reproducible chromatogram was obtained. To locate the fragments with Alz-50 immunoreactivity within the chromatogram, we dot blotted each 0.5-ml HPLC fraction with Alz-50 antibody. Reactivity was observed in 2 regions. One region consisted of broad peaks with retention times ranging from 100 to $135 \mathrm{~min}$. SDS-PAGE revealed that this region contained noncleaved $\tau$ and very large fragments. Based on the intensity of the protein on Coomassie blue-stained gels of $\tau$ protein in this portion of the chromatogram compared to standards, we estimated that the noncleaved protein constituted a maximum of $25 \%$ of the original sample. The second region with Alz-50 reactivity consisted of the sharp peaks designated 1-3 in Figure 2A. SDSPAGE of each of these late fractions revealed 2 bands, both of which ran below the lowest molecular-weight mark of $6 \mathrm{kDa}$ (data not shown). The inaccuracy of molecular-weight determination by SDS-PAGE of $\tau$ fragments has been shown previously using bacterially expressed $\tau$ peptides (Lee et al., 1989).

\section{Sequence and single-ion FAB-MS of a carboxy-terminal $\tau$ fragment}

The amino termini of the immunoreactive fractions that eluted as peaks $1-3$ in Figure $2 A$ were determined by direct protein sequencing. In 2 of the fractions, there were 2 amino termini, the sequences of which could be deduced because they correlated with the known predicted $\tau$ sequence (Himmler et al., 1989) and because their concentrations differed (Table 1). One peptide began at lysine 402 and, because of the decline in repetitive yield with each cycle, reliable detection of PTH-amino acids could not be obtained after valine 427 in any fraction. The second peptide began at serine 416 and became undetectable after leucine 443. Both of these peptides represent known chymotryptic cleavage sites (Allen, 1986). We have observed the very significant fall in the repetitive yield at Edman cycle 2 in both samples I and II, consistent with the presence of a phosphate at serine 403. However, definitive identification of the phosphoamino acid awaits future investigation. The concentration of the PTH-amino acids close to the amino termini of the sequenced peptides was consistent with the amount of $\tau$ protein initially loaded minus the approximated uncleaved fraction. 
Table 1. Repetitive yield of sequence in HPLC fractions

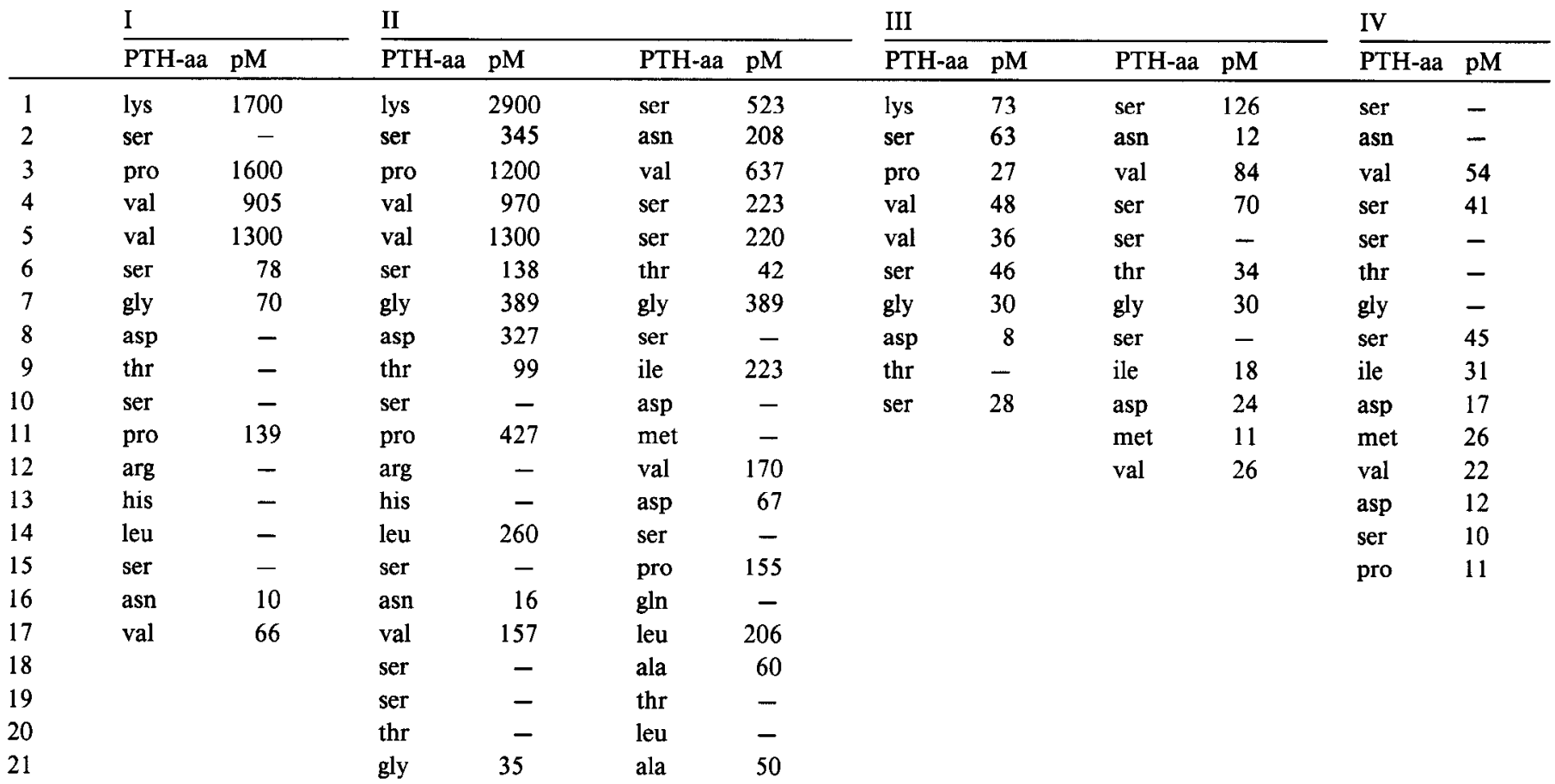

Repetitive yield: val $4>17=82 \%$
Repetitive yield: pro $3>11=88 \% \quad$ val $4>17=87 \%$
Repetitive yield:

Repetitive yield: ser $2>6=92 \% \quad$ val $3>12=88 \% \quad$ val $3>12=91 \%$

Four fractions around Alz-50-reactive peaks 1-3 are sequenced as described in Materials and Methods. In fraction I, the repetitive yield was $82 \%$ based on the yield of valine 4 and valine 17 . The repetitive yields for other peptides are indicated under the sequence. Note that fractions I-IV do not correspond to HPLC peaks $1-4$. aa, amino acid; pM, picomoles.

Sequencing of adjacent fractions, just before the first immunoreactive tube, that were nonreactive with $\mathrm{Alz}-50$ by dot blots revealed a peptide beginning at threonine 384 . No sequence was obtained beyond the last immunoreactive tube. The consistent inability to detect sample by gel electrophoresis, sequencing, and lack of immunoreactivity in HPLC peak 4 (Fig. $2 A$ ) suggested that it may be associated with a nonprotein reagent.

The data obtained from FAB-MS analysis of the fragments in each fraction are shown in Figure 3. The molecular masses correspond to carboxy-terminal $\tau$ peptides, and because the starting material was purified $\tau$ protein, it is unlikely that these masses could arise from any source other than $\tau$. Because the fractions were collected by time intervals, there is not a perfect correlation between the contents of each fraction and the HPLC peaks. While only 3 HPLC peaks contained a detectable sequence, the FAB-MS detected 4 discrete peptides. It is therefore likely that at least 2 of the peptides eluted together. Although the sequenator was unable to determine the carboxy termini of the peptides described above due to the successive decline in repeitive yield, the FAB-MS accurately demonstrates the full length of the peptides in each sample. In sample B (Fig. 3), 2 ion peaks were present that differed by an increment of 80 , consistent with phosphorylated and dephosphorylated forms of the same peptide. Because the nested peptide in samples $C$ and $\mathrm{D}$ did not contain a phosphate, it is probable that the phosphorylated amino acid lies between lysine 402 and leucine 415 . In this sequence, there are 3 serines and 1 threonine. However, one possibility is that those $\tau$ molecules with a phosphate at serine 416 may not be proteolyzed on their $\mathrm{N}$-terminal side.

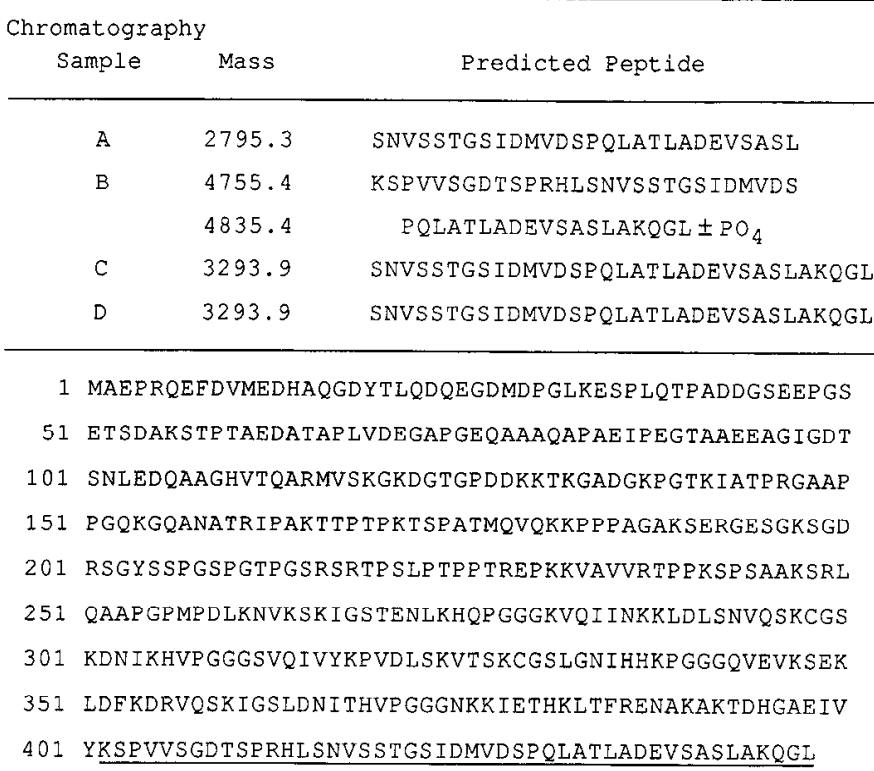

1 MAEPRQEFDVMEDHAQGDYTLQDQEGDMDPGLKESPLQTPADDGSEEPGS

51 ETSDAKSTP TAEDATAP LVDEGAPGEQAAAQAPAE IFEGTAAEEAGIGDT 101 SNLEDQAAGHVTQARMVSKGKDGTGPDDKKTKGADGKPGTKIATPRGAAP 151 PGQKGQANATRIPAKTTPTPKTSPATMQVQKKPPPAGAKSERGESGKSGD 201 RSGYSSPGSPGTPGSRSRTPSLPTPPTREPKKVAVVRTPPKSPSAAKSRL 251 QAAPGPMPULKNVKSK IGSTENLKHQPGGGKVQI INKKLDLSNVQSKCGS 301 KDN IKHVP GGGSVQIVYKPVDLSKVISKCGSL GNIHHKP GGGQVEVKSEK 351 LDFKDRVQSK I GSLDNITHVPGGGNKK IETHKLTFRENAKAKTDHGAEIV 401 YKSPVVSGDTSPRHLSNVSSTGS IDMVDSPQLATLADEVSASLAKQGL

Figure 3. Fast-atom-bombardment mass spectroscopy of carboxy-terminal $\tau$ fragments reactive with Alz-50. The mass of the ion peak is given for each sample. Note that samples $A-D$ do not correspond to fractions I-IV in Table 1 nor to peaks $1-4$ in Figure 1. Below the fragment masses, the entire bovine $\tau$ sequence is shown as described by Himmler et al. (1989). The isolated peptide fragments derive from the underlined region of the sequence. 

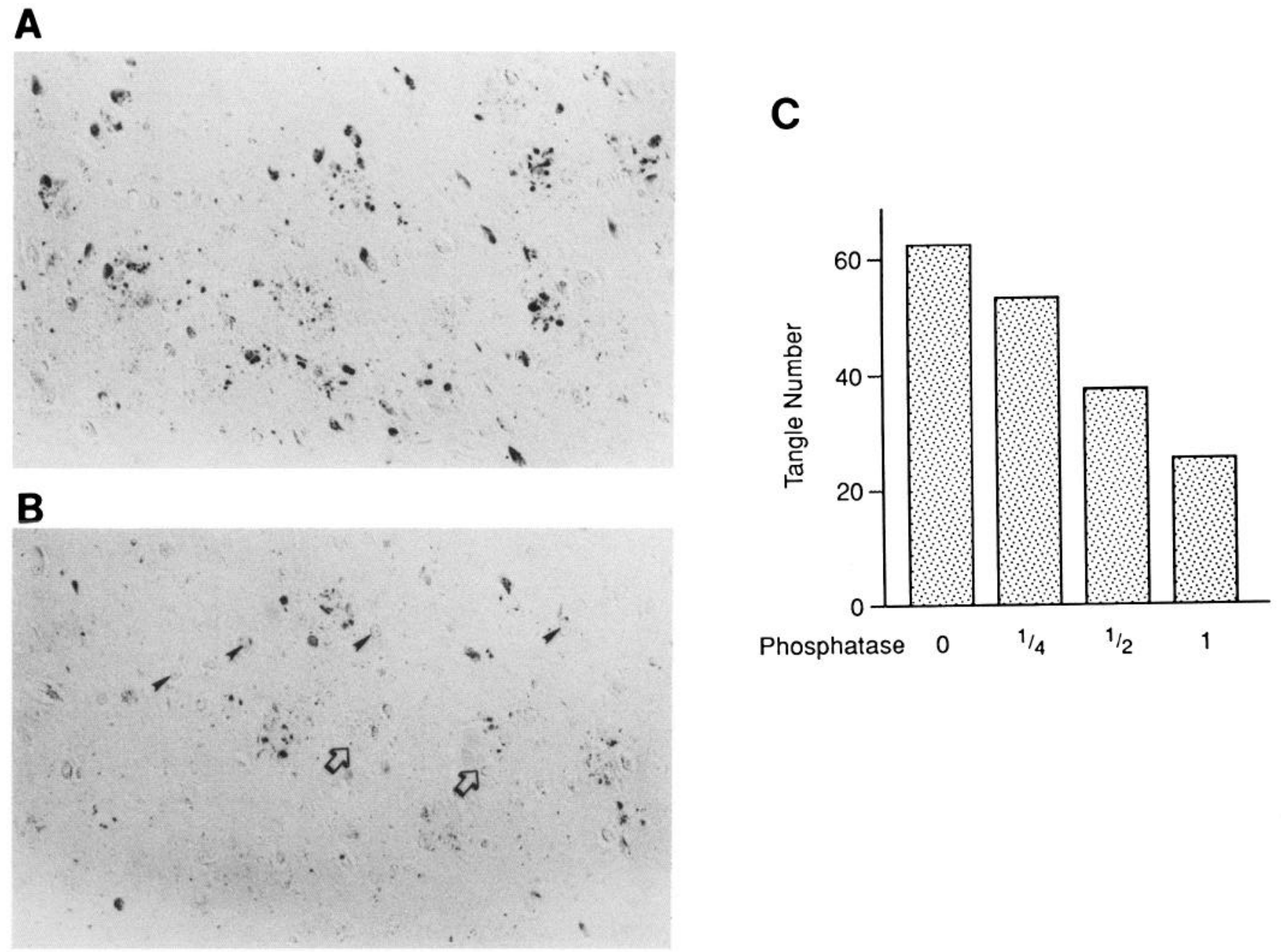

Figure 4. Alz-50 immunoreactivity is sensitive to acid phosphatase pretreatment. A, Alz-50-positive neuritic plaques and tangles in the CA1 area of the hippocampus after $2 \mathrm{hr}$ pretreatment in $0.1 \mathrm{M}$ acetate buffer $(\mathrm{pH}, 4.8$; control). $B$, After acid phosphatase (in acetate buffer) pretreatment, significant amounts of tangle-bearing neurons (arrows) were unstained with Alz-50. $(80 \times)$. C, Three different concentrations of acid phosphatases were used to pretreat sections. The highest phosphatase concentration was that indicated in Materials and Methods. Acid phosphatase reduced the tangle numbers in a concentration-dependent manner.

Hence, serine 416 cannot be excluded as a possible phosphorylation site.

\section{Alz-50 staining of NFTs is sensitive to acid phosphatase}

$\mathrm{Alz}-50$ intensely immunostained NFT, neuropil threads, and the neuritic component of plaques in $\mathrm{AD}$ brain sections (Fig. $4 A$ ). The staining pattern was indistinguishable from that seen with the Tau-1 antibody. The sensitivity of staining to phosphatase treatment, however, differed for these 2 antibodies. The Alz-50 staining of NFTs was diminished by acid phosphatase treatment in a dose-dependent manner (Fig. $4 B, C$ ) but not by alkaline phosphatase treatment. The Tau-1 staining of NFT was, on the other hand, modestly enhanced by pretreatment with either acid or alkaline phosphatase, similar to previous reports (Grundke-Iqbal et al., 1986; Wood et al., 1986).

\section{Phosphoserine diminishes Alz-50 staining}

The sensitivity of Alz-50 staining to acid phosphatase suggested that $\mathrm{Alz}-50$ is directed against a phosphoamino acid-containing sequence. If this is the case, a high concentration of phosphoami- no acid should adsorb out Alz-50 staining. In 7- $\mu \mathrm{m}$ paraffin sections of the AD hippocampus, Alz-50 immunolabeled $64 \pm$ 8 neuritic plaques and $241 \pm 15$ tangles $(N=3)$. When Alz-50 was preadsorbed with phosphoserine, the number of immunostained tangles decreased to $36 \%(P<0.02)$, and neuritic plaques decreased to $31 \%(P<0.05$; Fig. 5); the staining of neuropil threads was also significantly decreased (Fig. 5). In contrast, phosphothreonine failed to affect Alz-50 immunoreactivity, suggesting that Alz-50 is directed against an antigenic determinant containing phosphoserine. The same concentration of serine did not affect the immunostaining.

\section{Effect of phosphatase inhibitors during the sample preparation}

Alz-50 immunoreactivity detected on dot blot was higher in the $200,000 \times g$ pellet fractions prepared with phosphatase inhibitors than those prepared without them (Table 2). The immunodetection of Alz-50 reactivity on immunoblot of the same samples indicated that the presence of phosphatase inhibitors enhances the Alz-50 staining of several bands in this fraction (Fig. 6). This result is not due to the altered distribution of Alz- 

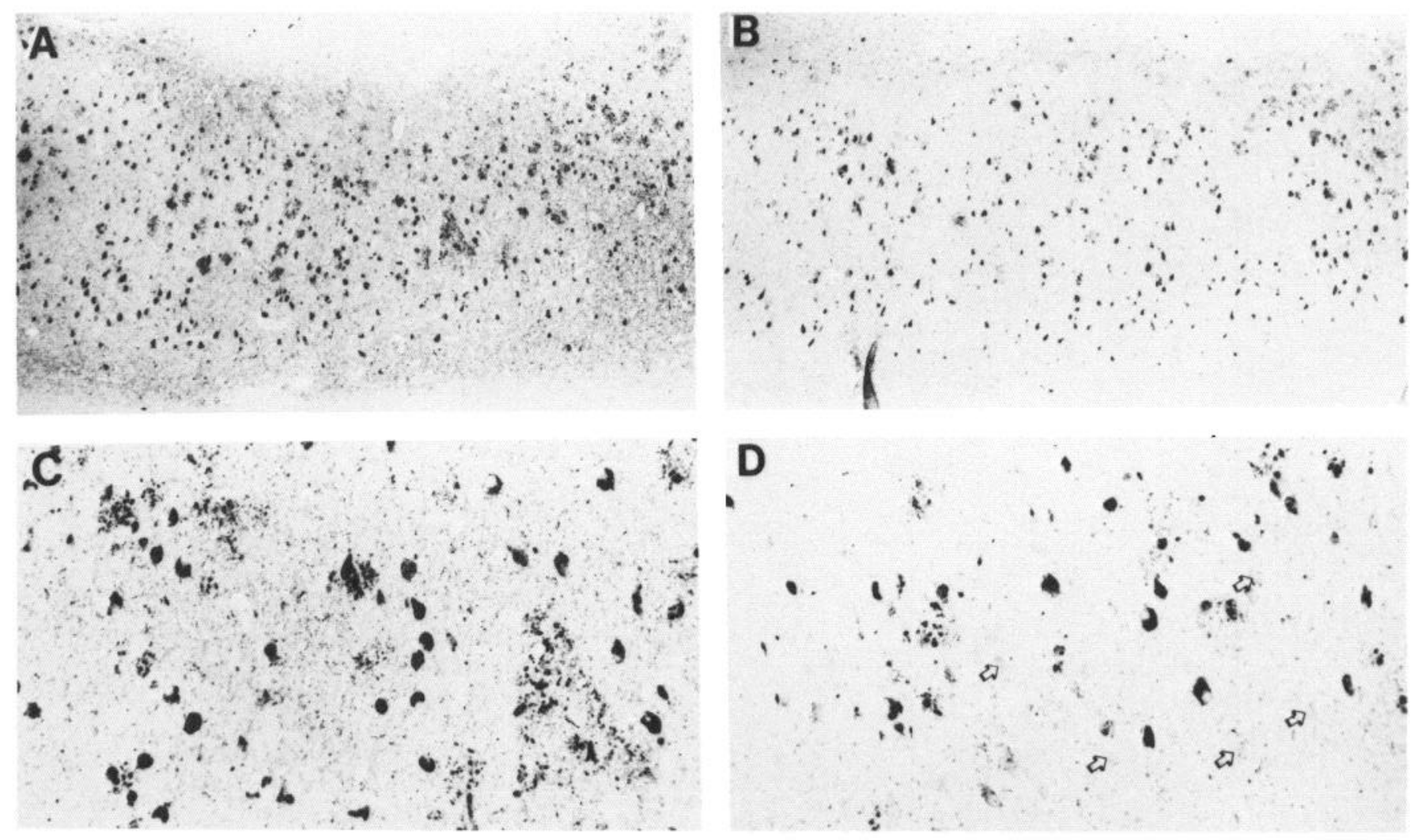

Figure 5. Phosphoserine diminished Alz-50 immunoreactivity. A, Classical Alz-50-positive plaques, tangles, and neuropil threads in the CA1 area and parasubiculum from an $\mathrm{AD}$ case $(24 \times) . B$. After preadsorption of Alz-50 with phosphoserine, a significant quantity of plaque, tangles, and threads was unstained $(24 \times)$. $C$, Same as $A$ at higher power $(76 \times) . D$, Same as $B$ at $76 \times$. Abundant, unstained, tangle-bearing neurons $($ arrows) were observed.

50 reactivity, because the similar enhancement of Alz-50 immunoreactivity was observed in other fractions. The inclusion of phosphatase inhibitors in 4 different preparations from $4 \mathrm{AD}$ brains demonstrated a $227 \%$ increase in reactivity by dot immunoassay compared to fractions prepared without phosphatase inhibitors (Table 2). The same preparations resulted in the reduction of Tau-1 immunoreactivity to various degrees (Table 2, Fig. 6). In the presence of phosphatase inhibitors, the Alz-50 reactive doublet of approximately $M_{\mathrm{r}} 65,000$ appears in some preparations (Fig. 6, lane 4). These results are best interpreted by assuming that Alz-50 immunoreactivity depends upon the presence of a phosphate, while Tau-1 immunoreactivity is masked by a phosphate. To confirm the effectiveness of phosphatase inhibitors, phosphate was assayed in purified bovine $\tau$. When prepared in the presence of phosphatase inhibitors, 3.6 $\pm 0.45 \mathrm{~mol}(N=3)$ phosphate per mol $\tau$ protein were detected. The same preparation without the phosphatase inhibitors gave a value of $2.0 \mathrm{~mol}$ phosphate per mol $\tau$ protein. It is likely that endogenous phosphatases remove a significant percentage of the phosphate from $\tau$ during standard purification procedures. Our estimate of the $\tau$ phosphate content is a minimal estimate because many of the phosphates may be labile and lost at the time of death, as has been demonstrated for microtubule-associated protein 2 (MAP2) (Tsuyama et al., 1987).

\section{Immunochemical probes for a phosphotyrosine}

Although no tyrosines are present within the chymotryptic peptides studied here, there is a tyrosine that is 1 residue amino to the studied peptide beginning at lysine 306 . Because phospho- tyrosines can be detected immunochemically, we sought to exclude the presence of phosphotyrosine in $\tau$ with 3 different antibodies. None of these phosphotyrosine antibodies immunoreacted with tangles in brain sections or with $\tau$ prepared in the presence of phosphatase inhibitors. We concluded that either $\tau$ does not contain a phosphotyrosine or, if it does, it is extremely labile.

\section{Discussion}

Alz-50 stains most strongly the doublet around $M_{\mathrm{r}} 60,000$ when brain homogenates are prepared without phosphatase inhibi-

Table 2. Effect of the inclusion of phosphatase inhibitors during homogenization

\begin{tabular}{llllrr} 
Case & \multicolumn{2}{l}{ Alz-50 reactivity } & & \multicolumn{2}{c}{ Tau-1 reactivity } \\
\cline { 2 - 3 } & - & + & & \multicolumn{1}{c}{+} \\
\hline 4386 & 1.13 & 2.88 & & 6.45 & 3.39 \\
4459 & 1.23 & 2.20 & & 13.37 & 9.12 \\
4513 & 1.60 & 3.44 & & 15.13 & 14.23 \\
4518 & 1.41 & 3.65 & & 12.59 & 2.96
\end{tabular}

Alz-50 and Tau-1 immunoreactivity was studied using dot blot technique on the high-speed pellet fractions prepared in the presence or absence of the cocktail of phosphatase inhibitors as described in Materials and Methods. Immunoreactivity was quantified by using a densitometric measurement of the autoradiogram with a laser densitometer (LKB Ultroscan XL) and is expressed as an integrated density (arbitrary unit). Linear range of the film was employed. In all 4 cases, Alz-50 immunoreactivity was higher when the sample was prepared with phosphatase inhibitors, whereas Tau-1 immunoreactivity was lower with phosphatase inhibitors. - , without phosphatase inhibitors; + , with phosphatase inhibitors. 

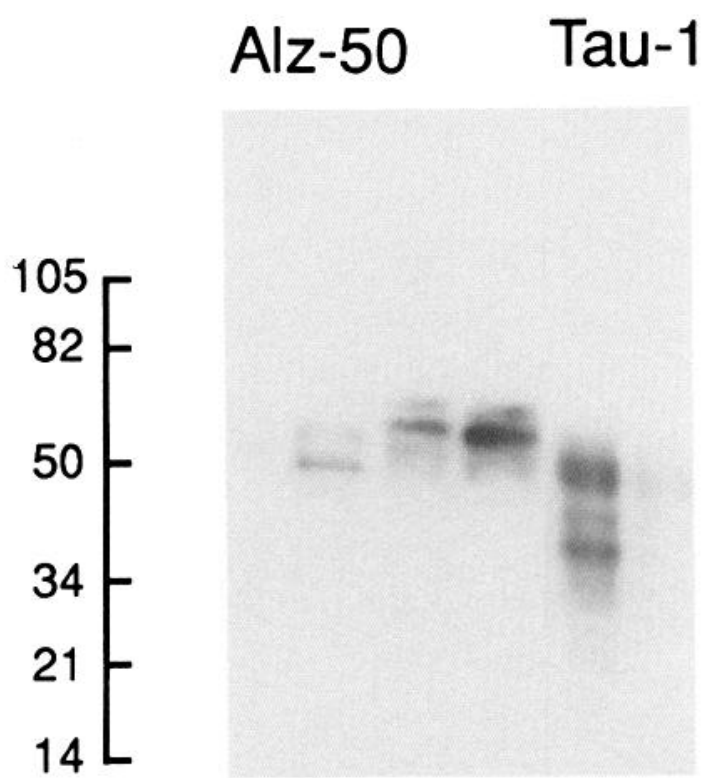

\section{Phosphatase inhibitors}

Figure 6. Effect of phosphatase inhibitors added during the preparation on Alz-50 and Tau-1 staining. Cocktails of phosphatase inhibitors as described under Materials and Methods were present $(+)$ or absent $(-)$ during the homogenization of brain samples. Lanes 1 and 2 are from $1 \mathrm{AD}$ cortex and lanes 3 and 4 are from another $\mathrm{AD}$ patient. Lanes 5 and 6 are brain samples identical to lanes 3 and 4 . The high-speed pellet was stained by Alz-50 or Tau-1. This autoradiogram was developed after a 10-hr exposure. Note that exposure time for the experiment reported in Figure 1 was 4 times longer than that for the current experiment. When samples are prepared in the presence of phosphatase inhibitors, Tau-1 staining is dramatically reduced. In this specific blot, Alz-50 stains higher-molecular-weight bands. In many samples, Alz-50 stains lower-molecular-weight bands as well. Tau-1 always stains lowermolecular-weight bands.

tors. The same doublet is also stained with Tau-1 monoclonal antibody. Using homogenates prepared with phosphatase inhibitors, Alz-50 staining by dot immunoassay was invariably stronger than those prepared without phosphatase inhibitors, and the molecular weight of doublet most strongly stained by Alz-50 shifted up to $M_{\mathrm{r}} 65,000$. Because the higher-molecularweight doublet was not stained by the monoclonal antibody Tau-1 (but was stained by Alz-50), it is likely that phosphorylation of the Tau-1 site both retards the migration of $\tau$ by SDSPAGE and masks the epitope. The phosphorylation of $\tau$ sequence recognized by Alz-50 does not seem to be involved in the retardation of $\tau$ migration in SDS-PAGE, because the Alz50 reactivity of both the fast- and slow-migrating species of $\tau$ is sensitive to acid phosphatase. The region of the Tau-1 epitope has delimited to a 19-amino acid-sequence amino terminal to the repeated sequences involved in microtubule binding (Kosik et al., 1988). The distinct location of the Alz-50 epitope reported here is consistent with the differential staining pattern observed on immunoblots and the differential response to phosphatases.

The Alz- 50 reactivity of proteolytically cleaved $\tau$ protein fragments separated on HPLC suggested the reactive site to be within the 47 amino acids between lysine 402 and the terminus. The localization of phosphate by FAB-MS between lysine 402 and serine 416 and the sensitivity of Alz-50 reactivity to the phosphoserine but not to the phosphothreonine competition argues for serine 403, 407, 411, or 416 as an Alz-50-reactive site. The decline in the repetitive yield at Edman degradation cycle 2 in some samples is consistent with the presence of phosphoserine at position 403. The definitive determination of the site awaits future investigation. This phosphate is very likely present in vivo and does not affect the migraton of $\tau$ on gels. Its proximity to the microtubule-binding sequences permits the speculation that it may have a regulatory role in the binding of $\tau$ to microtubules, perhaps via an allosteric role in reversibly regulating conformation. The phosphorylation of MAPs can down-regulate the microtubule steady state (Margolis and Wilson, 1979) and diminish their ability to promote microtubule polymerization (Lindwall and Cole, 1984a). This apparent effect was achieved by both CaM kinase II in vitro and by as yet uncharacterized kinases in the crude microtubule preparation, both of which catalyze phosphorylation associated with a mobility shift (Baudier and Cole, 1987; Ishiguro et al., 1988).

The phosphate-containing peptide in $\tau$ begins with the sequence KSPV, which is homologous to the multiphosphorylation repeat found in the neurofilament proteins (V. M.-Y. Lee et al., 1988). In the neurofilament, this region was postulated to serve as a hinge that depends on the phosphorylation state of the molecule. The identification of the particular phosphoamino acid within the isolated peptide cannot be determined from our data; it may be the serine within the KSPV or any of 3 other serines in the peptide. Although previous work has suggested that $\tau$ is a substrate for CaM kinase II (Yamamoto et al., 1983; Schulman, 1984; Baudier and Cole, 1987), it is unlikely that CaM kinase II phosphorylates the Alz-50 site because none of the possible phosphoamino acids within the peptide are canonical for CaM kinase II. Furthermore, in vitro labeling of $\tau$ by the CaM kinase II did not label any of the amino acids within the phosphopeptide identified by FAB-MS (Kosik et al., 1987), and unlike CaM kinase II-dependent phosphorylation, the phosphate at the Alz-50 site is not associated with a mobility shift.

Evidence from several laboratories has pointed to altered phosphorylation as a feature of $\mathrm{AD}$ pathology. There is increased in vitro phosphorylation of an $M_{\mathrm{r}}-60,000$ (P60) substrate protein in AD (Saitoh and Dobkins, 1986). PKC levels are decreased in both the brain (Cole et al., 1988) and fibroblasts (Huynh et al., 1989), and in vitro phosphorylation of an $M_{\mathrm{r}}-86,000$ PKC substrate is decreased (Cole et al., 1988). There are decreased levels of casein kinase II (CK-II) (Iimoto et al., 1990). Some reports have suggested that $\tau$ is aberrantly phosphorylated in AD (Grundke-Iqbal, 1986; Ihara et al., 1986; Wood et al., 1986; Iqbal et al., 1989). However, it is not clear whether the increased incorporation of phosphate into $\mathrm{AD} \tau$ is due to phosphorylation at normally phosphorylated sites or aberrant sites. Because the increased phosphorylation of P60 in AD appears to parallel the distribution of NFTs (Saitoh et al., 1988), it is possible that this same kinase phosphorylates $\tau$ in the NFT. Recently, we have found that CK-II antiserum immunoreacts with AD NFTs (Iimoto et al., 1990). One of the possible sites of a phosphoamino acid in the peptide identified by FAB-MS corresponds to a CKII consensus sequence. This site is serine 407 in the presence of a phosphothreonine at position 410 to provide the required acidic moiety.

In conclusion, we have demonstrated that $\mathrm{Alz}-50$ recognizes 
an epitope of $\tau$ which most likely contains a phosphate. The result is consistent with its localization within the 14-amino acid C-terminal to the tubulin-binding domain of $\tau$, though the rigorous demonstration of this point must await future research. It is interesting to note that acid phosphate treatment of the brain section and phosphoserine adsorption of Alz-50 eliminated the NFT staining of some neurons but not of others, suggesting that the Alz-50 epitope may be more complex than mere phosphorylation can explain.

\section{References}

Al-Ghoul WM, Miller MW (1989) Transient expression of Alz-50 immunoreactivity in developing rat neocortex: a marker for naturally occurring neuronal death? Brain Res 481:361-367.

Allen $G$ (1986) Sequencing of proteins and peptides. In: Laboratory techniques in biochemistry and molecular biology (Work TS, Burdon RH, eds), p 59. Amsterdam: Elsevier.

Bancher C, Brunner C, Lassmann H, Budka $H$, Jellinger K, Wiche $G$, Seitelberger F, Grundke-Iqbal I, Iqbal K, Wisniewski HM (1989) Accumulation of abnormally phosphorylated $\tau$ precedes the formation of neurofibrillary tangles in Alzheimer's disease. Brain Res 477: 90-99.

Baudier J, Cole RD (1987) Phosphorylation of tau proteins to a state like that in Alzheimer's brain is catalyzed by a calcium/calmodulindependent kinase and modulated by phospholipids. J Biol Chem 262 : 17577-17583.

Baudier J, Lee S-H, Cole RD (1987) Separation of the different microtubule-associated tau protein species from bovine brain and their mode II phosphorylation by $\mathrm{Ca}^{2+} /$ phospholipid-dependent protein kinase C. J Biol Chem 262:17584-17590.

Biemann K (1986) Methods for protein sequencing. Anal Chem 58: $1288 \mathrm{a}-1300 \mathrm{a}$.

Binder LI, Frankfurter A, Rebhun LI (1985) The distribution of tau in the mammalian central nervous system. J Cell Biol 101:13711378.

Butler M, Shelanski ML (1986) Microheterogeneity of microtubuleassociated $\tau$ proteins is due to differences in phosphorylation. $\mathrm{J}$ Neurochem 47:1517-1522.

Cole G, Dobkins KR, Hansen LA, Terry RD, Saitoh T (1988) Decreased levels of protein kinase $C$ in Alzheimer brain. Brain Res 452: 165-174.

Daniel, TO, Tremble PM, Frackelton AR, Williams LT (1985) Purification of platelet-derived growth factor receptor by using an antiphosphotyrosine antibody. Proc Natl Acad Sci USA 82:2684-2687.

Goedert M, Spillantini MG, Potier MC, Ulrich J, Crowther RA (1989) Cloning and sequencing of the cDNA encoding an isoform of microtubule-associated protein tau containing four tandem repeats: differential expression of tau protein mRNAs in human brain. EMBO J 8:393-399.

Grundke-Iqbal I, Iqbal K, Tung Y-C, Quinlan M, Wisniewski HM, Binder LI (1986) Abnormal phosphorylation of the microtubuleassociated protein $\tau$ (tau) in Alzheimer cytoskeletal pathology. Proc Natl Acad Sci USA 83:4913-4917.

Himmler A, Drechsel D, Kirschner MW, Martin DW (1989) Tau consists of a set of proteins with repeated C-terminal microtubulebinding domains and variable N-terminal domains. Mol Cell Biol 9: 1381-1388.

Hoshi M, Nishida E, Miyata Y, Sakai H, Miyoshi T, Ogawara H, Akiyama T (1987) Protein kinase $C$ phosphorylates tau and induces its functional alterations. FEBS Lett 217:237-241.

Huynh TV, Cole G, Katzman R, Huang K-P, Saitoh T (1989) Reduced PK-C immunoreactivity and altered protein phosphorylation in Alzheimer's disease fibroblasts. Arch Neurol 46:1195-1199.

Hyman BT, Van Hoesen GW, Wolozin BL, Davies P, Kromer LJ, Damasio AR (1988) Alz-50 antibody recognizes Alzheimer-related neuronal changes. Ann Neurol 23:371-379.

Ihara Y, Nukina N, Miura R, Ogawara M (1986) Phosphorylated tau protein is integrated into paired helical filaments in Alzheimer's disease. J Biochem 99:1807-1810.

Iimoto DS, Masliah E, DeTeresa R, Terry RD, Saitoh T (1990) Aberrant casein kinase II in Alzheimer's disease. Brain Res 507:273-280.

Iqbal K, Grundke-Iqbal I, Smith AJ, George L, Tung Y-C, Zaidi T
(1989) Identification and localization of a $\tau$ peptide to paired helical filaments of Alzheimer disease. Proc Natl Acad Sci USA 86:56465650 .

Ishiguro K, Ihara Y, Uchida T, Imahori K (1988) A novel tubulindependent protein kinase forming a paired helical filament epitope on tau. J Biochem 104:319-321.

Joachim CL, Morris JH, Selkoe DJ, Kosik KS (1987) Tau epitopes are incorporated into a range of lesions in Alzheimer's disease. J Neuropathol Exp Neurol 46:611-622.

Kondo J, Honda T, Mori H, Hamada Y, Miura R, Ogawara M, Ihara $Y$ (1988) The carboxyl third of tau is tightly bound to paired helical filaments. Neuron 1:827-834.

Kosik KS, Lee G, Kennedy MB (1987) Type II calcium/calmodulindependent kinase phosphorylates tau protein in the region of the mouse repeal. Am Soc Biol Chem Abstr: 24.

Kosik KS, Orecchio LD, Binder LI, Trojanowski J, Lee V, Lee G (1988) Epitopes that span the tau molecule are shared with paired helical filaments. Neuron 1:817-825.

Kosik KS, Orecchio LD, Bakalis S, Neve RL (1989) Developmentally regulated expression of specific tau sequences. Neuron 2:1389-1397.

Kowall NW, Kosik KS (1987) Axonal disruption and aberrant localization of tau protein characterize the neuropil pathology of Alzheimer's disease. Ann Neurol 22:639-643.

Ksiezak-Reding H, Davies P, Yen S-H (1988) Alz-50, a monoclonal antibody to Alzheimer's disease antigen, cross-reacts with $\tau$ proteins from bovine and normal human brain. J Biol Chem 263:7943-7947.

Lee G, Cowan N, Kirschner M (1988) The primary structure and heterogeneity of tau protein from mouse brain. Science 239:285-288.

Lee G, Neve R, Kusik KS (1989) The microtubule binding domain of tau protein. Neuron 2:1615-1624.

Lee VM-Y, Otvos L, Carden MJ, Hollosi M, Dietzschold B, Lazzarini RA (1988) Identification of the major multiphosphorylation site in mammalian neurofilaments. Proc Natl Acad Sci USA 85:998-2002.

Lindwall G, Cole RD (1984a) Phosphorylation affects the ability of tau protein to promote microtubule assembly. J Biol Chem 259:53015305.

Lindwall G, Cole RD (1984b) The purification of tau protein and the occurrence of two phosphorylation states of tau in brain. J Biol Chem 259:12241-12245.

Love S, Saitoh T, Quijada S, Cole GM, Terry RD (1988) Alz-50, ubiquitin and tau immunoreactivity of neurofibrillary tangles, Pick bodies and Lewy bodies. J Neuropathol Exp Neurol 47:393-405.

Margolis RL, Wilson L (1979) Regulation of the microtubule steady state in vitro by ATP. Cell 18:673-679.

Mori H, Hamada Y, Kawaguchi M, Honda T, Kondo J, Ihara Y (1989) A distinct form of tau is selectively incorporated into Alzheimer's paired helical filaments. Biochem Biophys Res Commun 159:12211226.

Morla AO, Wang JYJ (1986) Protein tyrosine phosphorylation in the cell cycle of BALB/c 3T3 fibroblasts. Proc Natl Acad Sci USA 83: 8191-8195.

Nieto A, Correas I, Montejo de Garcini E, Avila J (1988) A modified form of microtubule-associated tau protein is the main component of paired helical filaments. Biochem Biophys Res Commun 154:660667.

Nukina N, Kosik KS, Selkoe DJ (1988) The monoclonal antibody, Alz-50, recognizes tau proteins in Alzheimer's disease brain. Neurosci Lett 87:240-246.

Saitoh T, Dobkins KR (1986) Increased in vitro phosphorylation of a $M_{\mathrm{r}} 60,000$ protein in brain from patients with Alzheimer's disease. Proc Natl Acad Sci USA 83:9764-9767.

Saitoh T, Hansen LA, Dobkins KR, Terry RD (1988) Increased $M_{\mathrm{r}}$ 60,000 protein phosphorylation is correlated with neocortical neurofibrillary tangles in Alzheimer's disease. J Neuropathol Exp Neurol $47: 1-8$.

Schulman H (1984) Phosphorylation of microtubule-associated proteins by a $\mathrm{Ca}^{2+} /$ calmodulin-dependent protein kinase. J Cell Biol 99: 11-19.

Stul JT, Buss JE (1977) Phosphorylation of cardiac troponin by cyclic adenosine $3^{\prime}: 5^{\prime}$-monophosphate-dependent protein kinase. J Biol Chem 252:851-857.

Towbin H, Staehelin R, Gordon J (1979) Electrophoretic transfer of proteins from polyacrylamide gels to nitrocellulose sheets: procedure and some applications. Proc Natl Acad Sci USA 76:4350-4354.

Trojanowski JQ, Schuck T, Schmidt ML, Lee VM-Y (1989) Distri- 
bution of tau proteins in the normal human central and peripheral nervous system. J Histochem Cytochem 37:209-215.

Tsuyama S, Terayama Y, Matsuyama S (1987) Numerous phosphates of microtubule-associated protein 2 in living rat brain. J Biol Chem 262:10886-10892.

Vallee RB (1982) A taxol-dependent procedure for the isolation of microtubules and microtubule-associated proteins (MAPs). J Cell Biol 92:435-442.

White MF, Maron R, Kahn CR (1985) Insulin rapidly stimulates tyrosine phosphorylation of a $M_{\mathrm{r}}-185,000$ protein in intact cells. Nature 318:183-186.

Wischik CM, Novak M, Thøgersen HC, Edwards PC, Runswick MJ, Jakes R, Walker JE, Milstein C, Roth M, Klug A (1988) Isolation of a fragment of tau derived from the core of the paired helical filament of Alzheimer disease. Proc Natl Acad Sci USA 85:4506-4510.
Wolozin BL, Pruchnicki A, Dickson DW, Davies P (1986) A neuronal antigen in the brains of Alzheimer patients. Science 232:648-650.

Wolozin BL, Scicutella A, Davies P (1988) Reexpression of a developmentally regulated antigen in Down syndrome and Alzheimer disease. Proc Natl Acad Sci USA 85:6202-6206.

Wood JG, Mira SS, Pollock NJ, Binder LI (1986) Neurofibrillary tangles of Alzheimer disease share antigenic determinants with the axonal microtubule-associated protein tau ( $\tau)$. Proc Natl Acad Sci USA 83:4040-4043.

Yamamoto H, Fukunaga K, Tanaka E, Miyamoto E (1983) $\mathrm{Ca}^{2+}$ and calmodulin-dependent phosphorylation of microtobule-associated protein 2 and $\tau$ factor, and inhibition of microtubule assembly. $J$ Neurochem 41:1119-1125. 